\title{
VARIASI KARAKTER MORFOLOGIS LIMA JENIS SAGU (Metroxylon sp) DI PULAU SAPARUA
}

\author{
Lepinus Sahetapy ${ }^{1}$, Ritha L. Karuwal ${ }^{2}$ \\ ${ }^{1}$ Alumni Program Studi Pendidikan Biologi \\ ${ }^{2}$ Staf Pengajar Program Studi Pendidikan Biologi
}

E-mail: lepinussahetapy@yahoo.com; rithakaruwal@yahoo.com

\begin{abstract}
Background: Sago (Metroxylon sp) is one of food commodities that contains many carbohydrates, so it serves as a staple food for some regions in Indonesia such as Maluku, Papua and Sulawesi. Sago can also be used as raw material for food industry such as bagea, sago pearl, pastry, wet cake, noodle, biscuit, cracker and vermicelli. Various uses of sago cause attention in terms of development and conservation. Saparua Island is one of the areas in the Maluku archipelago with sago potential that is wide enough. There are 5 types of sago in the area such as sago tuni, sagu molat, sago eataru, sagu ihur, and sago thorn rattan.

Methods: This research took place in February-March 2014 by conducting exploration on location and samples selected by proposive sampling. For each quantitative parameter such as height, length, width, using a measuring instrument of ruler, roll meter while qualitative parameters such as shape, color can be observed visually.

Results: Exploration was conducted on February-March 2014 with morphological character parameters on vegetative and generative organs of 70 characters. The results of the study showed a varied morphological appearance in each variety. Visually, variations of morphological characters in the vegetative organ seen in the trunk character are height, surface, circumference, color. Leaf character has variation in leaf sponge, leaf bone flexibility, midst of base of midrib, midrib, midrib, midrib, midlet, child length, upper surface. Morphological characters in generative organs appear to vary in flower, ie, the length and width of the stem, the diameter of the flower. Variations in fruits such as shape, amount, and color while on the seeds are the color and weight.

Conclusion: There are variations of morphological characters in the five varieties of sago on Saparua Island in shape, size, and color, appearance of each organ either on stems, leaves, flowers, fruits and seeds.
\end{abstract}

Keywords: Variation, morphological characters, sago (Metroxylon sp), Saparua

\begin{abstract}
Abstrak
Latar Belakang: Sagu (Metroxylon sp) adalah salah satu komoditi bahan pangan yang banyak mengandung karbohidrat, sehingga dijadikan sebagai bahan makanan pokok untuk beberapa daerah di Indonesia seperti Maluku, Papua dan Sulawesi. Sagu juga dapat dimanfaatkan sebagai bahan baku industri pangan antara lain dapat diolah menjadi bahan makanan seperti bagea, mutiara sagu, kue kering, kue basah, mie, biskuit, kerupuk dan bihun. Pemanfaatan yang beranekaragam menyebabkan sagu perlu mendapat perhatian dalam hal pengembangan dan konservasi. Pulau Saparua termasuk salah satu daerah di kepulauan Maluku dengan potensi sagu yang cukup luas. Terdapat 5 jenis sagu di daerah tersebut diantaranya sagu tuni, sagu molat, sagu makanaru, sagu ihur, dan sagu duri rotan. Metode: Penelitian ini berlangsung pada Febuari-Maret 2014 dengan melakukan eksplorasi pada lokasi dan sampel dipilih secara proposive sampling. Untuk tiap parameter kuantitatif seperti tinggi, panjang, lebar, menggunakan alat ukur berupa penggaris, roll meter sedangkan parameter kualitatif seperti bentuk, warna dapat diamati secara visual.

Hasil: Eksplorasi dilakukan pada bulan Febuari-Maret 2014 dengan parameter karakter morfologis pada organ vegetatif dan generatif sebanyak 70 karakter. Hasil penelitian menunjukan adanya penampilan morfologis yang bervariasi pada masing-masing varietas. Secara visual, variasi karakter morfologis pada organ vegetatif terlihat pada karakter batang adalah tinggi, permukaan, lingkar, warna. Karakter daun memiliki variasi pada kelenturan anak daun, kelenturan tulang anak daun, lebar pangkal pelepah, panjang pelepah, bentuk pelepah, garis punggung pelepah, warna pelepah, jumlah anak, panjang anak, permukaan atas. Karakter morfologis pada organ generatif terlihat bervariasi pada bunga
\end{abstract}


yaitu panjang dan lebar tangkai, diameter bunga. Variasi pada buah seperti bentuk, jumlah, dan warna sedangkan pada biji adalah warna dan berat.

Kesimpulan: Terdapat variasi karakter morfologis pada ke lima varietas sagu di pulau Saparua pada bentuk, ukuran, warna, penampakan tiap organ baik pada batang, daun, bunga, buah dan biji.

Kata kunci: Variasi, karakter morfologis, sagu (Metroxylon sp), Saparua

\section{PENDAHULUAN}

Sagu (Metroxylon sp) merupakan salah satu komoditi bahan pangan yang banyak mengandung karbohidrat, sehingga dijadikan sebagai bahan makanan pokok untuk beberapa daerah di Indonesia seperti Maluku, Papua dan sebagian Sulawesi. Sagu juga dapat dimanfaatkan sebagai bahan baku industri pangan yang antara lain dapat diolah menjadi bahan makanan seperti bagea, mutiara sagu, kue kering, kue basah, mie, biskuit, kerupuk dan bihun (Harsanto, 1986).

Keberadaan sagu di Indonesia tersebar di beberapa propinsi, salah satunya propinsi Maluku yang terkenal dengan sagu sebagai bahan makanan pokok. Pulau Saparua merupakan salah satu daerah di Propinsi Maluku yang memiliki potensi sagu yang cukup luas dengan sebagian penduduknya menjadikan sagu sebagai bahan makanan pokok atau pun bahan makanan tambahan. Sagu di Pulaua Saparua tumbuh pada tiga macam kondisi lingkungan tumbuh yang berbeda, yaitu tanah kering, tanah rawa dan pinggir sungai. Tumbuhan sagu ditemukan paling banyak pada kondisi tanah rawa dan paling sedikit pada kondisi tanah pinggir sungai (Schuiling dan Flach, 1985).

Sagu yang tumbuh di Pulaua Saparua dikenal ada lima jenis sagu dengan nama lokal setempat, yaitu tuni, ihur, makanuru, duri rotan dan molat. Empat jenis pertama merupakan jenis sagu yang berduri, sedangkan jenis sagu molat tidak berduri. Sagu jenis molat mempunyai pati yang putih dan rasanya enak sehingga jenis sagu ini yang banyak diolah oleh penduduk setempat untuk dijadikan sebagai bahan makanan. (Louhenapessy dkk, 2012). Keragaman jenis sagu kemungkinan memiliki karakter morfologis yang berbedabeda. Penelitian ini dilakukan untuk mengetahui variasi karakter morfologis 5 jenis sagu di Pulau Saparua.

\section{MATERI DAN METODE}

Penelitian ini berlangsung pada Febuari-Maret 2014 dengan melakukan eksplorasi pada lokasi dan sampel dipilih secara proposive sampling.

Dalam melakukan karakterisasi menggunakan paduan deskriptor sagu harapan dan tantangan (Louhenapessy, $d k k$. 2010). Organ tanaman yang diamati adalah organ vegetatif yang meliputi 6 karakter batang, dan 32 karakter daun. Organ generatif terdiri dari 13 karakter bunga, 11 karakter buah dan 6 karakter biji.

Untuk tiap parameter kuantitatif seperti tinggi, panjang, lebar, menggunakan alat ukur berupa penggaris, roll meter sedangkan parameter kualitatif seperti bentuk, warna dapat diamati secara visual. Data selanjutnya dianalisis secara deskriptif untuk menggambarkan variasi di antara kelima jenis sagu tersebut.

\section{HASIL DAN PEMBAHASAN}

Berdasarkan hasil karakterisasi morfologis terdapat variasi diantara kelima varietas sagu di pulau Saparua. Variasi karakter morfologis ke lima varietas sagu tersebut dapat di lihat pada tabel 1 di bawah ini: 
Tabel 1. Variasi Karakter Morfologis Kelima Varietas Sagu di Pulau Saparua

\begin{tabular}{|c|c|c|c|c|c|}
\hline KARAKTER TANAMAN & SAGU TUNI & SAGU MOLAT & SAGU IHUR & SAGU MAKANARU & $\begin{array}{l}\text { SAGU DURI } \\
\text { ROTAN }\end{array}$ \\
\hline \multicolumn{6}{|l|}{ A. Karakter Batang } \\
\hline 1. Tinggi batang $(\mathrm{m})$ & 25 & 16 & 20 & 10 & 9 \\
\hline 2. Bentuk batang & Bulat dan lurus & Bulat dan lurus & Bulat dan lurus & Bulat dan lurus & Bulat dan lurus \\
\hline 3. Permukaan batang & Ada bekas pelepah & Ada bekas pelepah & Ada bekas pelepah & Ada bekas pelepah & Ada bekas pelepah \\
\hline 4. $\quad$ Diameter batang $(\mathrm{cm})$ & 160 & 120 & 165 & 136 & 116 \\
\hline 5. Warna batang & Coklat & Coklat kemerahan & Coklat & Coklat kemerahan & Coklat \\
\hline 6. Tebal pangkal batang (waah) & $2 \mathrm{~cm}$ & $2 \mathrm{~cm}$ & $2 \mathrm{~cm}$ & $2 \mathrm{~cm}$ & $2 \mathrm{~cm}$ \\
\hline \multicolumn{6}{|l|}{ B. Karakter Daun } \\
\hline 7. Bentuk daun & Lanset & Lanset & Lanset & Lanset & Lanset \\
\hline 8. Bentuk ujung daun & Meruncing & Meruncing & Meruncing & Meruncing & Meruncing \\
\hline 9. Bentuk pangkal daun & Membulat & Membulat & Membulat & Membulat & Membulat \\
\hline 10. Tata letak daun & Bersilang berhadap & $\begin{array}{l}\text { Bersilang } \\
\text { Berhadap }\end{array}$ & $\begin{array}{l}\text { Bersilang } \\
\text { berhadap }\end{array}$ & $\begin{array}{l}\text { Bersilang } \\
\text { berhadap }\end{array}$ & $\begin{array}{l}\text { Bersilang } \\
\text { berhadap }\end{array}$ \\
\hline 11. Tepi anak daun & Rata & Rata & Rata & Rata & Rata \\
\hline 12. Kelenturan anak daun & Lentur & Lentur & Agak lentur & Tidak lentur & Tidak lentur \\
\hline 13. Pertulangan daun & Sejajar & Sejajar & Sejajar & Sejajar & Sejajar \\
\hline 14. Kelenturan tulang anak daun & Lentur & Lentur & Tidak lentur & Tidak lentur & Tidak lentur \\
\hline 15. Susunan pelepah & Berselang seling & Berselang seling & Berselang seling & Berselang seling & Berselang seling \\
\hline 16. Lebar pangkal pelepah(cm) & 25 & 20 & 19 & 8 & 20 \\
\hline 17. Panjang pelepah daun(cm) & 100 & 150 & 175 & 50 & 150 \\
\hline 18. Bentuk pelepah daun & Berduri & Tidak berduri & Berduri & Berduri & Berduri \\
\hline 19. Garis punggung pelepah & Tidak bergaris & Bergaris & Tidak bergaris & Bergaris & Tidak bergaris \\
\hline 20. Warna pelepah daun & Hijau & $\begin{array}{l}\text { Hijau dengan bintik } \\
\text { bintik putih }\end{array}$ & $\begin{array}{l}\text { Hijau dengan bintik } \\
\text { bintik putih }\end{array}$ & Hijau & $\begin{array}{l}\text { Hijau tua dengan } \\
\text { bintik bintik putih }\end{array}$ \\
\hline 21. Panjang anak daun(cm) & 146 & 150 & 140 & 125 & 150 \\
\hline 22. Jarak antar daun $(\mathrm{cm})$ & 18 & 10 & 12 & 12 & 30 \\
\hline 23. Lebar anak daun(cm) & 10 & 10 & 8 & 6 & 9 \\
\hline 24. Tekstur atas daun & Kesat & Licin & Kesat & Agak Kesat & Agak Kesat \\
\hline 25. Tekstur bawah daun & Licin & Licin & Licin & Licin & Licin \\
\hline 26. Lebar tepian pangkal daun(cm) & 2 & 2 & 3 & 2 & 2 \\
\hline 27. Warna permukaan atas daun & Hijau tua & Hijau tua & Hijau tua & Hijau tua & Hijau tua \\
\hline
\end{tabular}

Lepinus Sahetapy dan Ritha L. Karuwal, Variasi Karakter Morfologi ... 107 


\begin{tabular}{|c|c|c|c|c|c|}
\hline 28. Warna permukaan bawah daun & Hijau muda & Hijau muda & Hijau muda & Hijau muda & Hijau muda \\
\hline 29. Panjang ibu tulang daun(cm) & 146 & 150 & 140 & 125 & 150 \\
\hline 30. Warna ibu tulang atas daun & Hijau tua & Hijau tua & Hijau tua & Hijau tua & Hijau tua \\
\hline 31. Warna ibu tulang bawah daun & Hijau muda & Hijau muda & Hijau muda & Hijau muda & Hijau muda \\
\hline 32. Panjang duri $(\mathrm{cm})$ & 3,5 & - & 1 & 8 & 1 \\
\hline 33. Bentuk duri & $\begin{array}{l}\text { Berbaris agak teratur, } \\
\text { sangat sedikit } \\
\text { persilangan antar duri }\end{array}$ & - & $\begin{array}{c}\text { Berbaris kurang } \\
\text { teratur, sedikit } \\
\text { persilangan antar } \\
\text { duri }\end{array}$ & $\begin{array}{l}\text { Berbaris sangat tidak } \\
\text { merata, banyak } \\
\text { persilangan antar duri }\end{array}$ & $\begin{array}{l}\text { Sangat padat } \\
\text { dengan struktur } \\
\text { tidak teratur }\end{array}$ \\
\hline 34. Warna duri & Coklat & - & Coklat & Coklat & Coklat tua \\
\hline 35. Warna pangkal duri & Coklat & - & Hitam & Coklat kemerahan & Coklat tua \\
\hline 36. Warna ujung duru & Coklat & - & Coklat & Coklat gelap & Coklat muda \\
\hline 37. Jumlah duri & 35 & - & 15 & 13 & 17 \\
\hline 38. Kekerasan dan kelenturan duri & Keras, tidak lentur & - & Lebih keras, lentur & Lunak, tidak lentur & Keras, agak lentur \\
\hline \multicolumn{6}{|l|}{ C. Karakter bunga } \\
\hline 39. Panjang bunga(cm) & 10 & 5 & 5,5 & 5 & 5 \\
\hline 40. Panjang tangkai bunga(cm) & 60 & 25 & 25 & 22 & 27 \\
\hline 41. Lebar tangkai bunga(cm) & 2 & 2 & 2 & 2 & 2 \\
\hline 42. Posisi tandan & $\begin{array}{l}\text { Duduk pada ibu } \\
\text { tangkainya }\end{array}$ & $\begin{array}{l}\text { Duduk pada ibu } \\
\text { tangkainya }\end{array}$ & $\begin{array}{l}\text { Duduk pada ibu } \\
\text { tangkainya }\end{array}$ & $\begin{array}{l}\text { Duduk pada ibu } \\
\text { tangkainya }\end{array}$ & $\begin{array}{l}\text { Duduk pada ibu } \\
\text { tangkainya }\end{array}$ \\
\hline 43. Bentuk tandan & Bercabang & Bercabang & Bercabang & Bercabang & Bercabang \\
\hline 44. Penampakan tandan & Nyata & Nyata & Nyata & Nyata & Nyata \\
\hline 45. Bentuk bunga & Buah sirih (sirih buah) & $\begin{array}{l}\text { Buah sirih (sirih } \\
\text { buah) }\end{array}$ & $\begin{array}{l}\text { Buah sirih (sirih } \\
\text { buah) }\end{array}$ & Buah sirih (sirih buah) & $\begin{array}{l}\text { Buah sirih (sirih } \\
\text { buah) }\end{array}$ \\
\hline 46. Warna bunga mentah & Coklat tua & Coklat tua & Coklat tua & Coklat tua & Coklat tua \\
\hline 47. Warna bunga kering & Coklat putih & Coklat putih & Coklat putih & Coklat putih & Coklat putih \\
\hline 48. Jumlah cabang pada bunga & 13 & 7 & 7 & 10 & 8 \\
\hline 49. Warna tangkai bunga mentah & Coklat tua & Coklat tua & Coklat tua & Coklat tua & Coklat tua \\
\hline 50. Warna tangkai bunga kering & Coklat muda & Coklat muda & Coklat muda & Coklat muda & Coklat muda \\
\hline 51. Bentuk tangkai bunga & Bercabang & Bercabang & Bercabang & Bercabang & Bercabang \\
\hline \multicolumn{6}{|l|}{ D. Karakter Buah } \\
\hline 52. Bentuk buah & $\begin{array}{l}\text { Bulat, seperti buah } \\
\text { salak }\end{array}$ & $\begin{array}{l}\text { Bulat, seperti buah } \\
\text { salak }\end{array}$ & $\begin{array}{l}\text { Bulat, seperti buah } \\
\text { salak }\end{array}$ & $\begin{array}{l}\text { Bulat, seperti buah } \\
\text { salak }\end{array}$ & $\begin{array}{l}\text { Bulat, seperti buah } \\
\text { salak }\end{array}$ \\
\hline 53. Warna buah mentah & Hijau kekuningan & Hijau kekuningan & Hijau kekuningan & Hijau kekuningan & Hijau kekuningan \\
\hline
\end{tabular}

Lepinus Sahetapy dan Ritha L. Karuwal, Variasi Karakter Morfologi ... 108 
Biopendix, Volume 1, Nomor 2, Maret 2015, hlm. 105-111

\begin{tabular}{|c|c|c|c|c|c|}
\hline 54. Warna buah kering & Coklat kemerahan & Coklat kemerahan & Coklat kemerahan & Coklat kemerahan & Coklat kemerahan \\
\hline 55. Posisi buah & Ketiak & Ketiak & Ketiak & Ketiak & Ketiak \\
\hline 56. Jumlah buah & 6 & 7 & 9 & 6 & 7 \\
\hline 57. Panjang tangkai buah(cm) & 25 & 30 & 27 & 22 & 26 \\
\hline 58. Lebar tangkai buah(cm) & 2 & 2 & 2 & 2 & 2 \\
\hline 59. Jumlah buah per tangkai & 6 & 7 & 9 & 6 & 7 \\
\hline 60. Jumlah buah per tandan & 6 & 7 & 9 & 6 & 7 \\
\hline 61. Berat buah per tangkai (gr) & 2 & 2 & 3 & 2 & 2 \\
\hline 62. Berat buah per tandan $(\mathrm{kg})$ & 1,2 & 1,2 & 1,7 & 1 & 1,9 \\
\hline \multicolumn{6}{|l|}{ E. Karakter Biji } \\
\hline 63. Jumlah biji & 3 & 3 & 3 & 3 & 3 \\
\hline 64. Bentuk biji & Seperti biji salak & Seperti biji salak & Seperti biji salak & Seperti biji salak & Seperti biji salak \\
\hline 65. Warna biji mentah & Putih bening & Putih bening & Putih bening & Putih bening & Putih bening \\
\hline 66. Warna biji kering & Hitam & Hitam & Hitam & Hitam & Hitam \\
\hline 67. Berat biji kering 3 biji (gr) & 2,27 & 2,94 & 2,68 & 3,56 & 2,32 \\
\hline 68. Berat biji kering 1 biji (gr) & 0,72 & 1,13 & 0,95 & 1,30 & 1,03 \\
\hline
\end{tabular}


Hasil penelitian menunjukan bahwa umumnya sagu memiliki tinggi yang bervariasi antara 9-25 m. Panjang pelepah daun antara 7-13 $\mathrm{m}$. panjang anak daun antara $125-150 \mathrm{~cm}$. Warna daun adalah hijau tua dan hijau muda. Warna bunga coklat muda sampai coklat tua. Bentuk buah bulat. Warna buah hijau kekuningan. Berat biji antara 6,27-7,23 gram. Hal ini sesuai dengan pendapat Louhenapessy, dkk (2012), menyatakan bahwa sagu memiliki ciri-ciri morfologi antara lain tinggi pohon mencapai $20 \mathrm{~m}$, panjang pelepah berkisar dari 6-13 m. Pasangan anak daun 60-85. Panjang anak daun antara 90-170 cm. Daunnya berwarna hijau muda sampai hijau tua. Warna bunga merah kecoklatan. Bentuk buah bulat dengan warna coklat kekuningan. Berat biji 5,3 gram. Menurut Riska (2011), sagu ini memiliki lingkar batang berkisar 130-158 cm, panjang pelepah 5-8 m, panjang anak daun berkisar antara 125-162 $\mathrm{cm}$, warna daun hijau, hijau muda dan hijau tua.

Secara visual, variasi berdasarkan karakter morfologis pada organ vegetatif terlihat jelas pada karakter batang adalah tinggi, permukaan, lingkar, warna. Karakter daun memiliki variasi pada kelenturan anak daun, kelenturan tulang anak daun, lebar pangkal pelepah, panjang pelepah, bentuk pelepah, garis punggung pelepah, warna pelepah, jumlah anak, panjag anak, permukaan atas. Karakter morfologis pada organ generatif terlihat jelas pada bunga yaitu panjang dan lebar tangkai, diameter bunga. Variasi pada buah antara lain bentuk, jumlah, warna. Variasi pada biji warna, berat.

Terdapat variasi karakter morfologis pada masing-masing varietas dipengaruhi oleh berbagai faktor baik faktor lingkungan, genetis, maupun faktor bias pada saat melakukan pengoleksian dan karakterisasi morfologis di lapangan. Dua jenis yaitu sagu Tuni dan sagu Ihur yang memiliki kondisi habitat pertumbuhan di daerah rawa yang berair tawar atau daerah rawa yang bergambut dan di daerah sepanjang aliran sungai, sedangkan tiga jenis lainya yaitu sagu Molat, sagu Makanaru, dan sagu Duri Rotan memiliki kondisi habitat pertumbuhan pada tanah liat berwarna kuning coklat atau hitam. Dengan demikian kelima jenis sagu memiliki kondisi lingkungan yang berbeda seperti jenis tanah, $\mathrm{pH}$ tanah, ketinggian tempat, curah hujan dan kelembaban sehingga menyebabkan sifat adaptasi yang berbeda.

Menurut Turukay (1986) bahwa tidak ada syarat tanah yang khusus bagi tumbuhan sagu. Selanjutnya dikemukakan bahwa tumbuhan ini dapat hidup di lahan atas (upland) dengan tanah vulkanik, latosol, andosol, dan podsolik atau di lahan bawah (lowland) dengan tanah grumusol, alluvial, gleisol dan tanah liat kaya bahan organik serta sagu juga dapat tumbuh di daerah rawa yang berair tawar dengan kandungan tanah liat $>70 \%$ dan bahan organik 30\% atau daerah rawa yang bergambut dan di daerah sepanjang aliran sungai. Pertumbuhan yang paling baik terjadi pada tanah yang kadar bahan organisnya tinggi dan bereaksi sedikit asam $\mathrm{pH}=5,5-6,5$. Dapat tumbuh di daerah dataran rendah sampai dengan ketinggian $700 \mathrm{~m}$ dpl. Ketinggian tempat yang optimal adalah $400 \mathrm{~m}$ dpl, ini dapat mempengaruhi kondisi lingkungamn dalam pengamatan karakter morfologis tumbuhan.

\section{KESIMPULAN}

Berdasarkan data hasil penelitian dan analisi yang telah dilakukan dapat disimpulkan bahwa. Terdapat variasi karakter morfologis pada kelima varietas sagu di pulau Saparua pada bentuk, ukuran, warna, penampakan tiap organ baik pada batang, daun, bunga, buah dan biji.

Oleh karena penelitian terhadap sagu masih sangat terbatas, maka diperlukan penelitian lanjutan berdasarkan hubungan kekerabatan fenetik 5 jenis sagu sehingga dapat melengkapi data karakteristik. Dalam karakterisasi morfologis perlu memperhatikan sifat kuantitatif dan kualitatif.

\section{DAFTAR PUSTAKA}

Harsanto, P. B. 1986. Budidaya dan Pengolahan Sagu. Kanisius. Yogyakarta.

Louhenapessy, J. E., M. Luhukay, J. Sahetapy, P. Alfons dan J. Riry. 2010. Sagu harapan dan tantangan, PT Bumi Aksara: Jakarta 
Louhenapessy, J. E., M. Luhukay, J. Riry. 2012. Mari Belajar Mengenal Sagu Untuk Sekolah Dasar Materi Dasar Penuntun Untuk Kurikulum Muatan Lokal. Seri I. Penerbit CV Anugerah Sejati. Jakarta Pusat.

Schuiling, D. L. dan M. Flach., 1985. Guidelines for the Cultivation of Sago Palm. Dept. Of Tropical Crop Science. Agric. Univ. Of Wageningen. The Netherlands.
Riska, K. I., Suliansyah., A. Syarif. 2011. Iventarisasai dan Karakterstik Keragaman Morfologis sagu (metroxylonsp) di kabupaten Pesisir selatan. Skripsi Fakultas Pertanian. Andalas. 69Hal. (Tidak dipublikasikan). Turukay, 1986. The Role Sago Palm in the Development of Integratet Farm System in the Maluku Province of Indonesia. Proceedings of the Third Internanational Sago Symposium. Tokyo. 